\title{
Production of reactive oxygen species by isolated mitochondria of the Antarctic bivalve Laternula elliptica (King and Broderip) under heat stress
}

\author{
K. Heise ${ }^{\mathrm{a}}$, S. Puntarulo ${ }^{\mathrm{b}}$, H.O. Pörtner ${ }^{\mathrm{a}}$, D. Abele A,* $^{\mathrm{a} *}$ \\ ${ }^{\mathrm{a}}$ Alfred Wegener Institute for Polar and Marine Research, Columbusstr., 27568 Bremerhaven, Germany \\ ${ }^{\mathrm{b}}$ Physical Chemistry - PRALIB, School of Pharmacy and Biochemistry, University of Buenos Aires, Buenos Aires, Argentina
}

Received 16 May 2002; received in revised form 30 September 2002; accepted 1 October 2002

\begin{abstract}
Formation of reactive oxygen species (ROS) in mitochondrial isolates from gill tissues of the Antarctic polar bivalve Laternula elliptica was measured fluorimetrically under in vitro conditions. When compared to the rates measured at habitat temperature $\left(1{ }^{\circ} \mathrm{C}\right)$, significantly elevated ROS formation was found under temperature stress of $7^{\circ} \mathrm{C}$ and higher. ROS formation correlated significantly with oxygen consumption in individual mitochondrial preparations over the entire range of experimental temperatures $\left(1-12{ }^{\circ} \mathrm{C}\right)$. ROS generation per $\mathrm{mg}$ of mitochondrial protein was significantly higher in state 3 at maximal respiration and coupling to energy conservation, than in state $4+$, where ATPase-activity is inhibited by oligomycin and only proton leakage is driving the residual oxygen consumption. The percent conversion of oxygen to the membrane permeant hydrogen peroxide amounted to $3.7 \%$ (state 3 ) and $6.5 \%($ state $4+$ ) at habitat temperature $\left(1{ }^{\circ} \mathrm{C}\right.$ ), and to $7 \%$ (state 3 ) and $7.6 \%$ (state $\left.4+\right)$ under experimental warming to $7{ }^{\circ} \mathrm{C}$. This is high compared to $1-3 \%$ oxygen to ROS conversion in mammalian mitochondrial isolates and speaks for a comparatively low control of toxic oxygen formation in mitochondria of the polar bivalve. However, low metabolic rates at cold Antarctic temperatures keep absolute rates of mitochondrial ROS production low and control oxidative stress at habitat temperatures. Mitochondrial coupling started to fall beyond $3{ }^{\circ} \mathrm{C}$, closely to pejus temperature $\left(4{ }^{\circ} \mathrm{C}\right)$ of the bivalve. Accordingly, the proportion of state 4 respiration increased from below $30 \%$ at $1{ }^{\circ} \mathrm{C}$ to over $50 \%$ of total oxygen consumption at $7{ }^{\circ} \mathrm{C}$, entailing reduced ADP/O ratios under experimental warming. Progressive mitochondrial uncoupling and formation of hazardous ROS contribute to bias mitochondrial functioning under temperature stress in vitro. Deduced from a pejus temperature, heat stress commences already at $5{ }^{\circ} \mathrm{C}$, and is linked to progressive loss of phosphorylation efficiency, increased mitochondrial oxygen demand and elevated oxidative stress above pejus temperatures.
\end{abstract}

(C) 2002 Elsevier Science Inc. All rights reserved.

Keywords: Mitochondria; Reactive oxygen species; Oxidative stress; Heat stress; Antioxidant; Laternula elliptica; Bivalve; Antarctic

\section{Introduction}

Mitochondria are major sources of reactive oxygen species (ROS) in mammalian and also in

*Corresponding author. Alfred-Wegener Institute for Polar and Marine Research, Department of Marine Ecophysiology and Ecotoxicology, Columbusstr., 27568 Bremerhaven, Germany. Tel.: +49-471-4831-1567; fax: +49-471-4831-1149.

E-mail address: abele@awi-bremerhaven.de (D. Abele). ectothermal cells. This implies higher ROS-formation rates per cell with increasing mitochondrial density. Thus, antioxidant enzyme (AOX) activities tend to be higher in metabolically active tissues like liver and gills as compared to muscle tissue in fish (Lemaire et al., 1993; Ansaldo et al., 2000), digestive gland vs. body wall in polychaetes (Buchner et al., 1996), or gills vs. mantle tissue 
in cephalopods (Zielinski and Pörtner, 2000). In a between species comparison this implies higher AOX activities in warm blooded mammals and birds as compared to cold blooded marine invertebrates.

Among other internal and external parameters, temperature is an important modulating factor of mitochondrial densities in marine ectotherms. Evolutionary adaptation of ectothermal species to constant low temperatures in polar environments requires increased mitochondrial densities to compensate for reduced mitochondrial performance in the cold (Guderley, 1998; Pörtner et al., 2000). A potential drawback of this compensation could consist in the concomitant increase of the level of mitochondrial formation of toxic oxygen radicals. Thus, studies comparing AOX activities in polar invertebrates and fish have found either similar activities (Cassini et al., 1993 for Mediterranean and polar fish; assayed at room temperature) or even elevated AOX activities in polar compared to Mediterranean bivalves (Regoli, 1992; assayed at $25^{\circ} \mathrm{C}$ ). A recent paper by Gieseg et al. (2000) documents 5-6 times higher plasma vitamin E levels in Antarctic as compared to temperate finfish, supporting the view that cold adapted marine ectotherms could be especially prone to oxygen radical induced damage.

We have measured oxygen radical production in mitochondria isolated from gills of an Antarctic sessile bivalve, the suspension feeder Laternula elliptica, an essentially stenothermal animal. Urban (1998) determined an upper lethal temperature $\left(\mathrm{LT}_{50}\right)$ of $14.9{ }^{\circ} \mathrm{C}$ for L. elliptica which is surprisingly high for sublittoral Antarctic species. Recent data by Pörtner et al. (unpublished, cf. Pörtner, 2001), however, display a pejus temperature at 4 ${ }^{\circ} \mathrm{C}$, beyond which a decreased level of aerobic scope limits ecological performance (activity and reproduction) and hence survival of the animals. Aerobic scope is lost and transition to anaerobic metabolism occurs between 6 and $9{ }^{\circ} \mathrm{C}$ (Peck et al., 2002). According to Pörtner (2001), pejus temperatures are more indicative of the limits of geographical distribution of a species, than the temperature extreme an organism can tolerate passively for some time until it dies. Thus, Urban (1998) showed that reburial of Laternula specimens was impaired already at $4{ }^{\circ} \mathrm{C}$, which is an indication that the aerobic scope for activity of the animals is below the survival requirements already at this temperature (cf. Pörtner, 2001).
The focus of this paper was to compare mitochondrial performance and ROS-formation rates of L. elliptica mitochondria to whole animal thermal limits, and to study the role of oxidative stress in a stenothermal Antarctic animal under heating. Moreover, AOX activities were assessed, to obtain an estimate of the animal's potential to suppress oxidative stress within and beyond the range of thermal tolerance. These data complement a recent study of mitochondrial functioning under warming in the same species (Pörtner et al., 1999) and can be compared to a parallel study of the temperate soft shell clam, Mya arenaria (Abele et al., 2002).

\section{Material and methods}

\subsection{Animal sampling and maintenance}

L. elliptica was collected from Potter Cove, King-George Island, South Shetland Islands $\left(62^{\circ} 14^{\prime} \mathrm{S} ; 58^{\circ} 40^{\prime} \mathrm{W}\right)$ between December 2000 and February 2001 by SCUBA diving. The Potter Cove L. elliptica stock reaches maximal densities of up to over 300 individuals per $\mathrm{m}^{2}$ in the shallow areas between 5 and 15-m water depth (Mercuri et al., 1998). Animals were dug from $10-\mathrm{cm}$ sediment depth and transferred to our aquarium system on the Argentinean base Jubany. Specimens were maintained in seawater aquaria without sediment at $1{ }^{\circ} \mathrm{C}$ for up to 3 days prior to experimentation. Animals were not fed and fresh specimens were collected every week.

\subsection{Isolation of mitochondria}

Mitochondria were isolated from gills of 1 or 2 freshly sacrificed L. elliptica. Approximately 6-8 $\mathrm{g}$ of gill tissue was finely chopped in $10 \mathrm{ml}$ ice cold homogenization buffer ( $400 \mathrm{mM}$ sucrose, 100 $\mathrm{mM} \mathrm{KCl,} 6 \mathrm{mM}$ EGTA, $3 \mathrm{mM}$ EDTA, $70 \mathrm{mM}$ Hepes, $2 \mu \mathrm{g} \mathrm{ml}^{-1}$ aprotinin, $1 \%$ bovine serum albumin at $\mathrm{pH}$ 7.3) modified after Moyes et al. (1985), following the protocol of Pörtner et al. (1999). Extraction of mitochondria was achieved with 3 passes $(200 \mathrm{rpm})$ in a pre-cooled glass/ Teflon-homogenizer after adding $20 \mathrm{ml}$ of buffer.

The homogenate was centrifuged at $1200 \times g$ and $2{ }^{\circ} \mathrm{C}$ for $10 \mathrm{~min}$ and the supernatant collected. The pellet was resuspended in another $30 \mathrm{ml}$ of homogenization buffer and centrifuged again at the same speed. The two supernatants were combined and centrifuged at $10000 \times g$ for $6 \mathrm{~min}$ to 
sediment the mitochondria. The resulting pellet was resuspended in 3-4 $\mathrm{ml}$ of assay medium (560 $\mathrm{mM}$ sucrose, $100 \mathrm{mM} \mathrm{KCl}, 10 \mathrm{mM} \mathrm{KH} \mathrm{KO}_{4}, 70$ $\mathrm{mM}$ Hepes, $5 \mathrm{mM}$ glutamate, $1 \mu \mathrm{g}$ aprotinin and $1 \%$ bovine serum albumin at $\mathrm{pH} 7.3$ ). This suspension of isolated mitochondria could be kept on ice throughout the measurements with no apparent loss of respiratory activity or energetic coupling during $7 \mathrm{~h}$.

Measurements of mitochondrial respiration and coupling were carried out using Clarke electrodes as described for $M$. arenaria mitochondria (Abele et al., 2002) at assay temperatures of 1, 3, 5, 7, 9 and $12{ }^{\circ} \mathrm{C}$. However, good coupling (respiratory control ratio (RCR) of 3 ) was only achieved when pyruvate $(0.4 \mathrm{mM})$ and not malate was used as respiratory substrate. Maximal respiration rates were achieved at a concentration of $0.15 \mathrm{mM}$ ADP in the respiration chamber, while with $M$. arenaria only $0.06 \mathrm{mM}$ ADP were needed. State $4+$ respiration was measured after addition of 2 $\mu \mathrm{g} \mathrm{ml}^{-1}$ oligomycin.

Oxygen solubility $\left(\beta_{\mathrm{O}_{2}}\right)$ for the assay medium at each experimental temperature was adopted from Johnston et al. (1994). Oxygen consumption measurements were corrected for the electrode drift at $100 \% \quad P_{\mathrm{O}_{2}}$ and at $0 \% \quad P_{\mathrm{O}_{2}}$. The RCR was calculated by dividing state 3 by state 4 respiration according to Estabrook (1967). ADP/O ratios were calculated by dividing the amount of added ADP by the amount of molecular oxygen consumed in state 3 respiration (Chance and Williams, 1955).

Fluorimetric detection of ROS was carried out with a Kontron Instruments SFM 25 fluorimeter and dihydrorhodamin 123 (DHR) as indicator dye, following the protocol outlined by Abele et al. (2002). DHR was dissolved in dimethylsulfoxide, which had previously been purged with nitrogen, at a concentration of $14.45 \mathrm{mM}$ and stored in aliquots of $50 \mu \mathrm{l}$ at $-30{ }^{\circ} \mathrm{C}$. Of this stock solution $2 \mu \mathrm{l}(\rightarrow 29 \mu \mathrm{M}$ DHR $)$ were added per $\mathrm{ml}$ of assay medium $(560 \mathrm{mM}$ sucrose, $100 \mathrm{mM} \mathrm{KCl}$, $10 \mathrm{mM} \mathrm{KH}_{2} \mathrm{PO}_{4}, 70 \mathrm{mM}$ Hepes, $5 \mathrm{mM}$ glutamate). The assays were thermostatted to between 1 and $12{ }^{\circ} \mathrm{C}$, parallel to the measurements of mitochondrial respiration. Cooling was achieved using a water-jacketed cuvette.

Measurements were carried out using between 100 and $300 \mu l$ of isolated mitochondria and following the same protocol as employed for the mitochondrial respiration assays. Calibration of
DHR oxidation was done with a xanthine oxidase (XOD; obtained from Sigma)/xanthine system at $3,5,7,9,12$ and $15^{\circ} \mathrm{C}$ in the SFM 25 fluorimeter, as previously described in Abele et al. (2002). ROS production in the XOD/xanthine system at all temperatures had been calibrated spectrophotometrically using cytochrome $c$ oxidation as a molar indicator with $\varepsilon_{550 \mathrm{~nm}}: 28.5$. DHR autoxidation in the assay buffer was tested and found to be independent of temperature in a range between 1 and $15^{\circ} \mathrm{C}$. Presuming a temperature independent chemical reaction between the produced ROS and the fluorescent probe (DHR) in the mitochondrial assays, an equation for DHR oxidation by ROS was determined from the fluorescence increase as:

nmolROS $\min ^{-1} \mathrm{ml}^{-1}=0.1772$

$\times \tan$ of fluorescence signal $\left(r^{2}=0.9573\right)$

The stability of DHR oxidation rates in each newly prepared assay medium without mitochondria was checked by measuring the fluorescence slope of the DHR-medium with $3 \mathrm{mU}$ XOD $\mathrm{ml}^{-1}$ and $50 \mu \mathrm{M}$ xanthine at $9{ }^{\circ} \mathrm{C}$. The variability between slopes of individual media was below $5 \%$ of the mean slope.

\subsection{Measurements of AOX activities in gill tissues}

Catalase (CAT E.C. 1.11.1.6) was extracted into $50 \mathrm{mmol} \mathrm{l}^{-1} \mathrm{~K}-\mathrm{Pi}$ buffer containing $1 \%$ Triton$\mathrm{X} 100(\mathrm{pH} 7.0,1: 9 \mathrm{w}: \mathrm{v})$ and measured according to Aebi (1985). Superoxide dismutase (SOD E.C. 1.15.1.1) activity in crude homogenates was measured using the XOD/cytochrome $c$ assay according to Livingstone et al. (1992). Assays were carried out using freshly sacrificed animals at $20{ }^{\circ} \mathrm{C}$ and data normalized to tissue wet weight.

\subsection{Statistics}

Values are given as means \pm S.D. Data were plotted as a function of temperature. ABTs were calculated from two-phase regressions (Super-Anova). Two intersecting lines were selected that fitted the data best, according to the method of the least sum of squares. Significant differences of the resulting slopes were analysed by Student's $t$-test.

Data of RCR, $\mathrm{MO}_{2}$ and $\mathrm{ADP} / \mathrm{O}$-ratios were tested for homogeneity of variance (Levene-test) and for normal distribution (Kolmogorov-Smirnov-test). If these tests resulted in a statistically significant difference $(P>0.05)$, data were trans- 


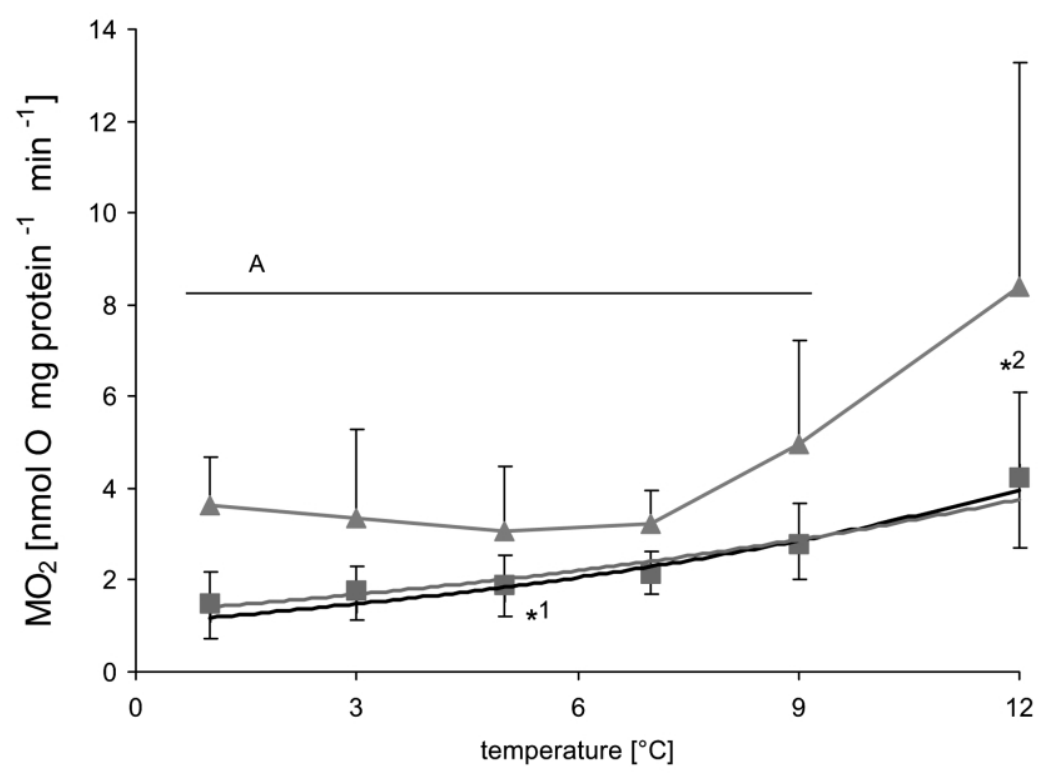

Fig. 1. Temperature dependence of the rates of state 3 respiration (triangles) and the rates of state 4 (diamonds) and state $4+$ respiration (squares) of gill mitochondria from $L$. elliptica. ' $\mathrm{A}$ ' indicates values in state 3 of significant difference from $12{ }^{\circ} \mathrm{C}(P<0.01)$. ' $*$ ' indicates significant differences from values at the lower temperature $(* 1$ state 4 and state $4+; P=0.024),(* 2$ state 4 and state $4+$, $P=0.041) ; n=8-21$; ANOVA, ANCOVA; Newman-Keuls-test. Exponential equations (Excel): state 4: $y=1.0662 \exp (0.1096 x), r^{2}=$ 0.9789 ; state $4+: y=1.2956 \exp (0.0889 x), r^{2}=0.9356$.

formed to logarithmic values. Significant changes in RCR, $\mathrm{MO}_{2}$ and $\mathrm{ADP} / \mathrm{O}$-ratios with temperature were evaluated by analysis of variance (ANOVA) and covariance (ANCOVA), as well as NewmanKeuls-test for post hoc-analysis at the $P \leqslant 0.05$ level using Statistica. ANCOVA was used for analysing the temperature dependence of state $4+$ oxygen consumption or ROS formation, using state 3 as a covariate. This was done because of the significant correlation of both parameters in state 3 and state $4+$ (Spearman-correlation for nonnormalized data, $n=66, P<0.01)$. Significant differences of groups of values were analysed by Contrast Analysis (Super-Anova).

\section{Results}

\subsection{Temperature dependence of mitochondrial functions in L. elliptica}

Fig. 1 depicts the temperature dependence of mitochondrial respiration in state 3 with pyruvate. Considering the habitat temperature range $(-1.9$ to $+1.3{ }^{\circ} \mathrm{C}$, according to Schloss et al., 1998) and a pejus temperature of $4{ }^{\circ} \mathrm{C}$ (Pörtner, 2001), heat stress for the mitochondria may already commence at $5{ }^{\circ} \mathrm{C}$. State 3 respiration stayed fairly constant between $3.6 \pm 1.07 \mathrm{nmolO} \mathrm{mg}^{-1} \mathrm{~min}^{-1}$ at $1{ }^{\circ} \mathrm{C}$ and $3.2 \pm 0.73 \mathrm{nmolO} \mathrm{mg} \mathrm{min}^{-1}$ at $7{ }^{\circ} \mathrm{C}$. The only significant increase with respect to the values at habitat temperature was found at $12{ }^{\circ} \mathrm{C}$ $\left(8.4 \pm 4.88 \mathrm{nmolO} \mathrm{mg}{ }^{-1} \mathrm{~min}^{-1}\right)$, whereas at $9{ }^{\circ} \mathrm{C}$ values were not significantly different from the measurements at lower temperatures. A $Q_{10}$ of 1.2 but no break temperature could be identified for state 3 respiration.

State 4 respiration (Fig. 1) displayed an exponential increase between 1 and $12{ }^{\circ} \mathrm{C} \quad(y=$ $1.06 \mathrm{e}^{0.1096 x} ; x=$ temperature; $y=$ resulting respiration rate; $r^{2}=0.979$ ) with no discernible break point temperature. Temperature dependency of state $4+$ respiration with oligomycin did not differ from state 4. A significant increment of state 4 (and state $4+$ ) respiration was found between 1 and $3{ }^{\circ} \mathrm{C}(P=0.024)$ and between 9 and $12{ }^{\circ} \mathrm{C}$ $(P=0.041) . Q_{10}$ values were 2.7 for state 4 and 2.1 for state $4+$ respiration between 1 and $12{ }^{\circ} \mathrm{C}$.

In general, respiration rates were higher and $Q_{10}$ values of both state 3 and state 4 respiration lower than in a previous study of L. elliptica mitochondria, especially in the low temperature range (Pörtner et al., 1999). RCR values and temperature dependency of respiratory rates were reduced and thermal stability of mitochondrial 
(a)

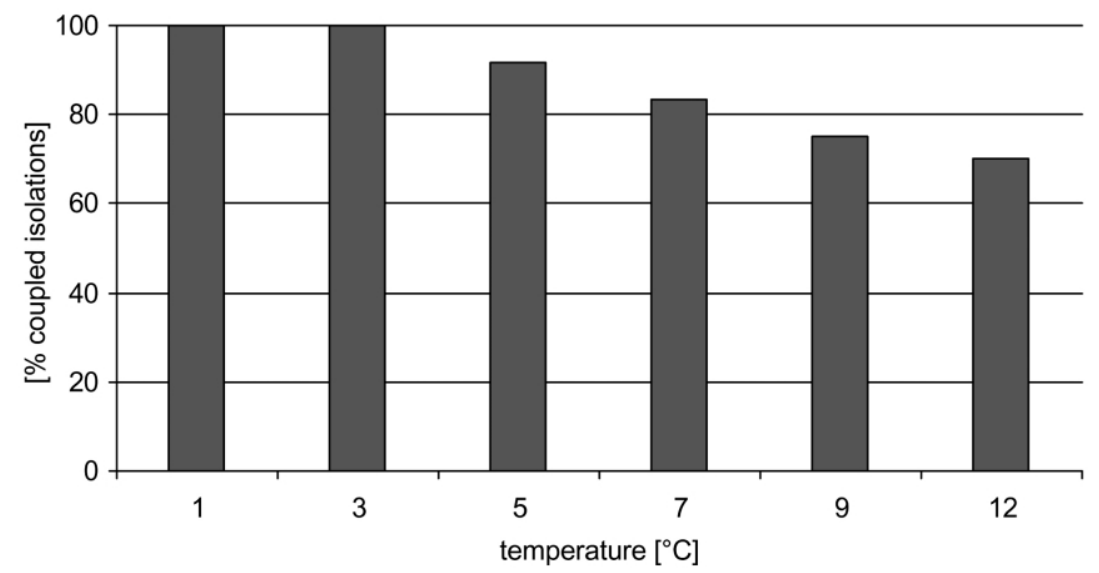

(b)

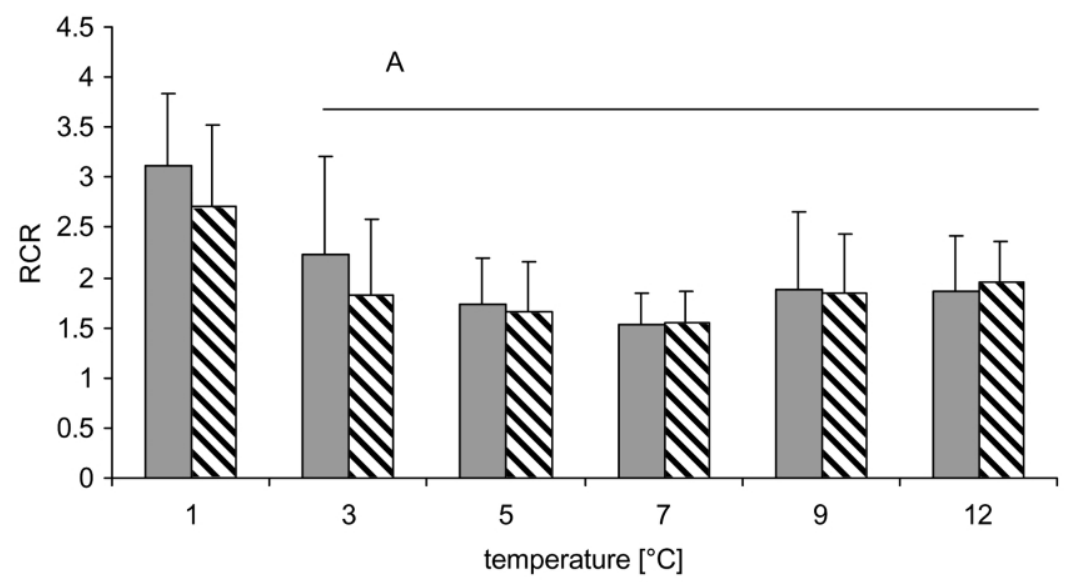

Fig. 2. (a) Percentage coupled mitochondrial isolates at each temperature of the total of 19 isolations performed. (b) Comparison of respiratory coupling ratios (RCR) of isolated gill mitochondria from L. elliptica determined from state 3 and state 4 respiration (RCR $3 / 4$; filled bars) and determined from state 3 respiration and respiration under oligomycin (RCR 3/4+; hatched bars). 'A' indicates values of significant differences from $1{ }^{\circ} \mathrm{C} ; n=8-19 ; P<0.01$; ANOVA; Newman-Keuls-test.

preparations was lower than found previously. However, energetic efficiency was maintained as indicated by similar ADP/O ratios. Some of these differences may be due to the higher pyruvate concentration ( 0.4 vs. $0.1 \mathrm{mM})$ at lower glutamate levels ( 5 vs. $20 \mathrm{mM}$ ) used as substrates in the present study for maximized state 3 and state 4 respiration. Moreover, the specimens used originated from two different populations and sites (Rothera base at the Southern peninsula in the earlier study; Jubany base at the Northern peninsula in the present study). Further investigations might reveal physiological differences between both populations involved in these patterns, despite similar thermal regimes.

Fig. 2a gives the percentage of coupled mitochondrial isolates at each temperature from the total of 19 isolations performed. Some isolates that were well coupled at 1 and $3{ }^{\circ} \mathrm{C}$ performed no coupled respiration at $5{ }^{\circ} \mathrm{C}$ or above. The percentage of uncoupled preparations increased with temperature to approximately $30 \%$ of all isolates at 12 ${ }^{\circ} \mathrm{C}$.

Fig. 2b depicts the temperature dependency of mitochondrial coupling as changes of respiratory coupling ratios RCR (state 3/4) and RCR + (state 


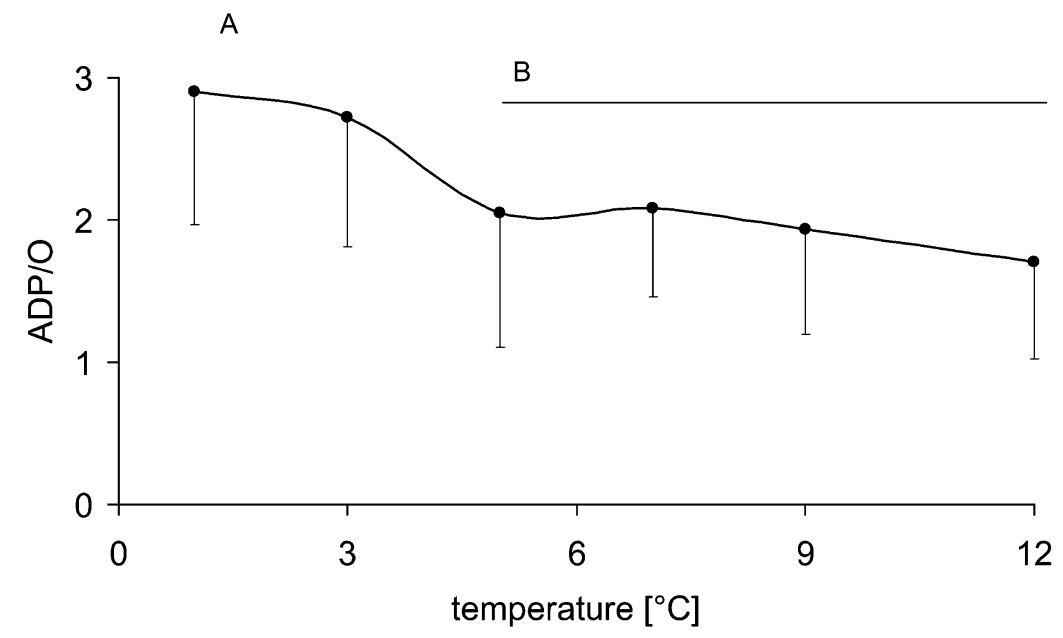

Fig. 3. Dependence of ADP/O-ratios of L. elliptica gill mitochondria on temperature; $n=8-19 ; P<0.01$; ANOVA; Contrast Analysis. 'A' indicates a group of values of significant difference from group ' $\mathrm{B}$ '.

$3 / 4+)$ between 1 and $12{ }^{\circ} \mathrm{C}$ in L. elliptica gill mitochondria. The graph shows only isolates that were coupled $(\mathrm{RCR}>1)$. There was a significant $(P<0.01)$ decrease of coupling between 1 and $3^{\circ}$ $C$ after which RCRs remained constant up to 12 ${ }^{\circ} \mathrm{C}$. Maximal coupling with an RCR of 3.1 (2.7 with RCR +) was found at $1{ }^{\circ} \mathrm{C}$. No significant difference $(P>0.05)$ was found between RCR and $\mathrm{RCR}+$ at any experimental temperature.

Dependency of ADP/O ratios (phosphorylation efficiency) on temperature is presented in Fig. 3. $\mathrm{ADP} / \mathrm{O}$ ratios were significantly higher at 1 and
$3{ }^{\circ} \mathrm{C}$ as compared to all higher temperatures $(P<$ $0.01)$.

\subsection{Temperature dependency of ROS production in mitochondrial isolates}

ROS production in isolates of L. elliptica gill mitochondria increased significantly with temperature in state 3 (Fig. 4, ANOVA $P<0.01, Q_{10}=$ 2.53), whereas the increase under state $4+$ conditions was less pronounced (ANCOVA $P=$ $\left.0.528, Q_{10}=2.05\right)$. However, also under oligomy-

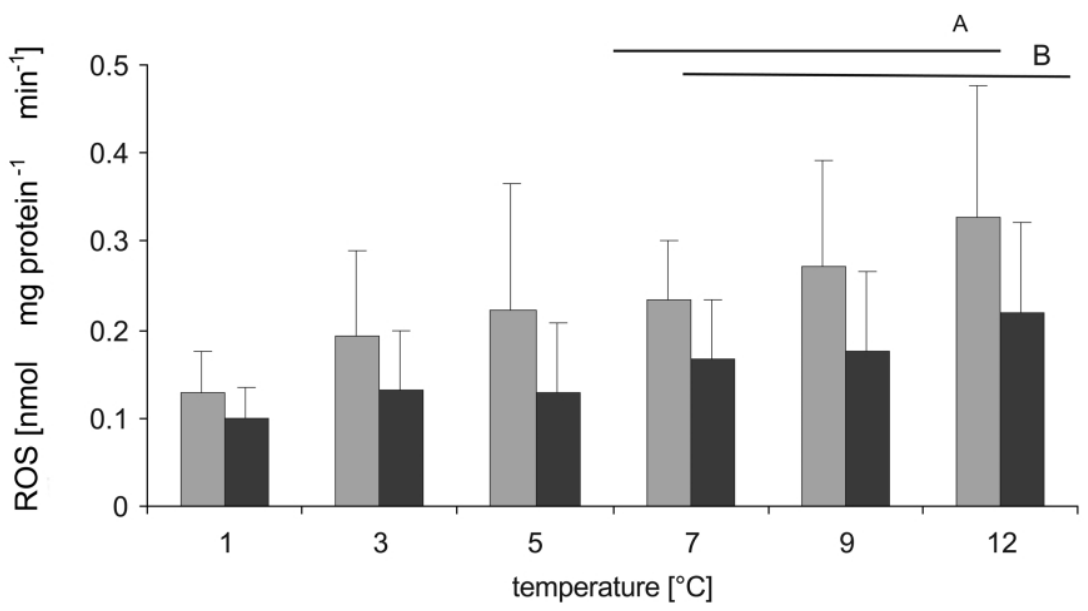

Fig. 4. Temperature dependence of total ROS formation from L. elliptica gill mitochondria under state 3 conditions (filled bars) and under state $4+$ conditions (hatched bars); $n=8-19$. 'A' depicts values of state 3 of significant difference from $1{ }^{\circ} \mathrm{C}$; ANOVA: $P<$ 0.01 ; Newman-Keuls-test: $P=0.028$. 'B' indicates values of state $4+$ of significant difference from $1{ }^{\circ} \mathrm{C}$; ANCOVA: $P=0.529$; Newman-Keuls-test: $P<0.01$. ' $*$ ' indicates significant difference from values at the lower temperature in state $4+$. 


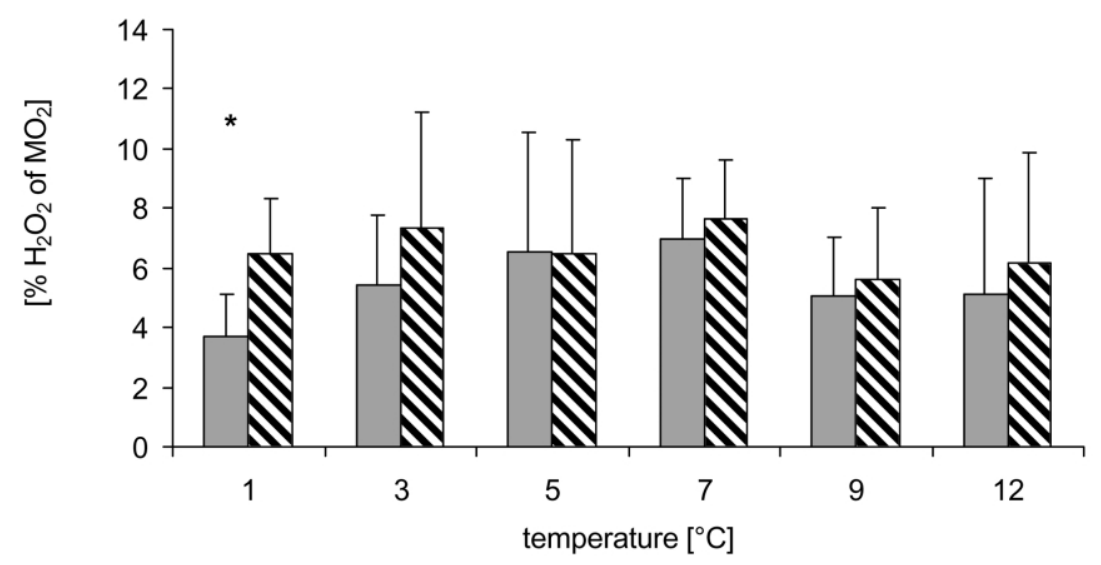

Fig. 5. Temperature dependence of percent fraction of total oxygen converted to hydrogen peroxide $\left(\% \mathrm{H}_{2} \mathrm{O}_{2}\right.$ of $\left.\mathrm{MO}_{2}\right)$ by L. elliptica gill mitochondria under state 3 (filled bars) conditions and under state $4+$ conditions (hatched bars); $n=7-18$. '*' significant difference between state 3 and state $4+$ at $1{ }^{\circ} \mathrm{C}$. ANOVA: $P=0.016$. Newman-Keuls-test: $P<0.01$.

cin, ROS production at 7,9 and $12{ }^{\circ} \mathrm{C}$ was significantly higher than the production rate at 1 ${ }^{\circ} \mathrm{C}$ (Newman-Keuls-test $\left.P<0.01\right)$. Generally, state 3 ROS production was significantly higher than state $4+$ ROS formation at one and the same temperature and, in both states, ROS formation in individual isolates correlated strongly with oxygen consumption (Spearman-correlation for non-normalized data; state 3: $r_{\text {spearman }}=0.26, n=66, P=$ 0.04 ; state $4+: r_{\text {spearman }}=0.44, n=66, P<0.01$ ). No Arrhenius break temperature could be identified in either respiratory state.

The percent rates of oxygen consumed that were converted to ROS and not to water in L. elliptica mitochondria (Fig. 5) were $3.7 \%$ in state 3 and $6.5 \%$ in state $4+$ at $1{ }^{\circ} \mathrm{C}$. Under temperature stress ROS conversion increased to between $5.1 \%\left(9{ }^{\circ} \mathrm{C}\right)$ and $7 \%\left(7{ }^{\circ} \mathrm{C}\right)$ in state 3 , and between $5.6 \%$ (9 $\left.{ }^{\circ} \mathrm{C}\right)$ and $7.6 \%\left(7{ }^{\circ} \mathrm{C}\right)$ in state $4+$. Significantly higher percent conversion of oxygen to ROS in state 3 than state $4+$ was found only at $1{ }^{\circ} \mathrm{C}$, and not during warming. This is in keeping with the elevated degree of thermal uncoupling of L. elliptica mitochondria at $3{ }^{\circ} \mathrm{C}$ and higher as shown in Fig. 2b. Accordingly, \% ROS formation correlated negatively with $\mathrm{RCR}+(y=-0.51 x+9.297 ; x=$ $\mathrm{RCR}+; y=$ resulting \% ROS formation; $P<0.01$, $n=59)$ and also with ADP/O ratio $(y=-0.35 x+$ 7.794; $x=\mathrm{RCR}+; y=$ resulting $\mathrm{ADP} / \mathrm{O}$ ratio; $P<$ $0.01, n=59$ ). Thus, better coupling and phosphorylation efficiency in L. elliptica gill mitochondria go along with lower \% conversion of oxygen to ROS.

\subsection{AOX activities in L. elliptica gill tissues}

The major enzymatic antioxidants catalase and SOD in gills were assayed at $20^{\circ} \mathrm{C}$. Their activities are indicative of the oxidative stress experienced by this organ. The $\mathrm{H}_{2} \mathrm{O}_{2}$ metabolizing catalase displayed an activity of $2.06 \pm 0.7 \mathrm{U} \mathrm{mg}^{-1}$ fresh weight, whereas the superoxide anion metabolizing SOD had an activity of $0.64 \pm 0.07 \mathrm{U} \mathrm{mg}^{-1}$ fresh weight gill. No significant temperature dependency between 0 and $20{ }^{\circ} \mathrm{C}$ was found for catalase activity of $L$. elliptica in vitro (data not shown).

\section{Discussion}

This paper gives a first record of temperature dependent mitochondrial ROS production in an Antarctic stenothermal bivalve. The idea was also to compare these data to a companion study (Abele et al., 2002) of mitochondria, isolated from the mantle tissue of the intertidal soft shell clam $M$. arenaria from the German Wadden Sea. Both animals have a comparable ecology as sessile suspension feeders. They dwell buried in soft sediments, siphon particles from the sediment water interface and occupy the same niche in the respective ecosystems (Ralph and Maxwell, 1977). In contrast to the cold stenothermal L. elliptica, $M$. arenaria is a eurythermal intertidal and subtidal species with a large thermal tolerance range, which spans from as low as $4{ }^{\circ} \mathrm{C}$ in winter to $18{ }^{\circ} \mathrm{C}$ during low tides on hot summer days (Anderson, 1978; Pedersen, 1992). This comparison might 

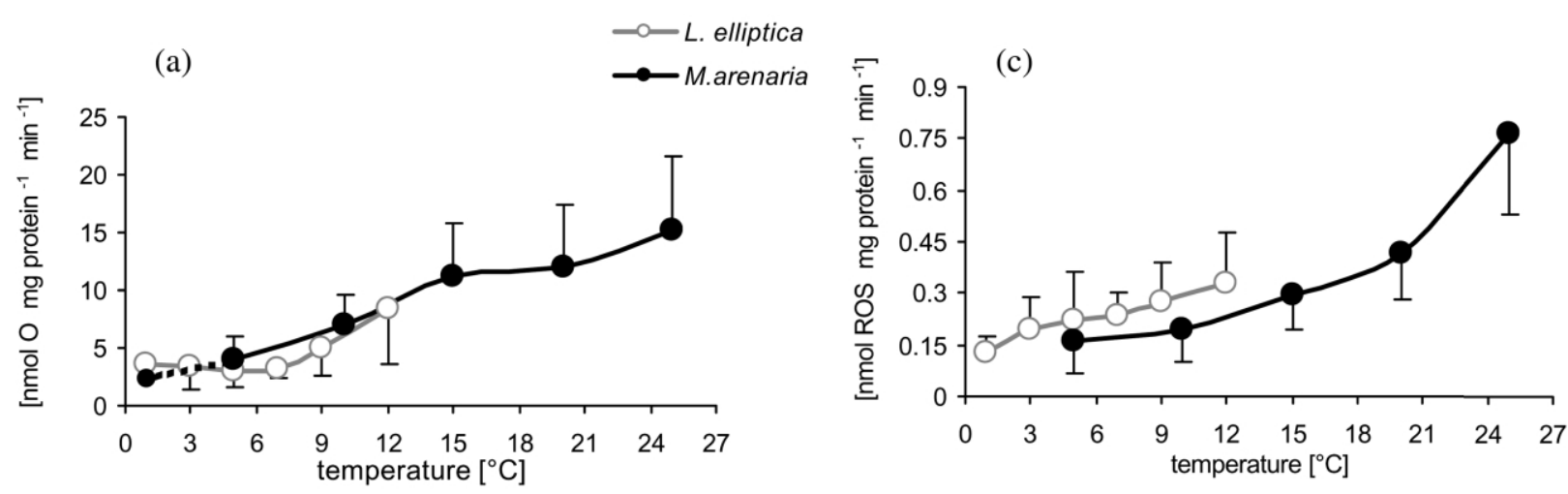

(b)
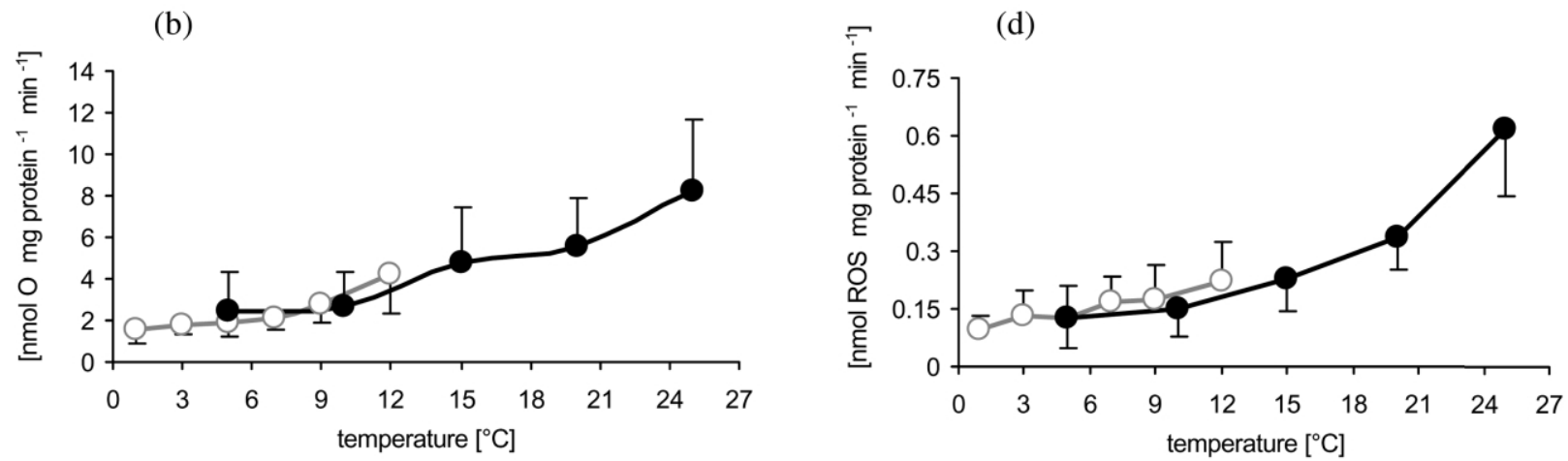

Fig. 6. Comparison of temperature dependent respiration in state 3 (a) and state $4+$ (b) and of ROS formation in state 3 (c) and state $4+$ (d) in mitochondria of L. elliptica gills (white dots, using glutamate and an excess of pyruvate as a substrate) and M. arenaria mantle tissue (black dots, using malate as a substrate). Substrates were chosen which yielded the highest state 3 respiration rates and comparable RCRs at the respective habitat temperatures. Dashed line in (a) for extrapolation of $M$. arenaria state 3 respiration to 1 ${ }^{\circ} \mathrm{C}$. Data for M. arenaria are from Abele et al. (2002).

help to understand the role that ROS formation and oxidative stress phenomena may play in the frames of thermal tolerance in marine ectotherms. We were especially interested to know how ROS production per mitochondrion (per mg mitochondrial protein) would compare in the Antarctic and the boreal species at a common, as well as at the respective habitat temperature for each species, and, secondly, whether mitochondrial dysfunction under stressfully high temperatures might involve oxidative stress.

\subsection{Formation of ROS in marine ectothermal mitochondria at cold temperatures}

ROS formation is perceived to cover between 1 and $3 \%$ of overall oxygen consumption in most heretofore studied mitochondrial isolates (Boveris and Chance, 1973; Sohal and Weindruch, 1996;
Sastre et al., 2000). In the Antarctic bivalve, $L$. elliptica, but also in the temperate soft shell clam, percent rates of ROS formation were tentatively higher, amounting to between 3.7 and $7.6 \%$ in $L$. elliptica (Fig. 5) and to between 2.6 and 5\% in M. arenaria (Abele et al., 2002), with highest conversion rates of $\mathrm{O}_{2}$ to $\mathrm{ROS}$ at the upper extremes or outside the respective habitat temperature range. Absolute ROS formation, normalized to $\mathrm{mg}$ of mitochondrial protein and compared at a common assay temperature, ranged insignificantly higher in the polar than the temperate clam under state 3 (Fig. 6c), while no difference was observed under state $4+$ (Fig. 6d) conditions.

If the mitochondria are compared at the respective habitat temperatures $\left(1{ }^{\circ} \mathrm{C}\right.$ : L. elliptica; 5-12 ${ }^{\circ} \mathrm{C}: M$. arenaria), basal, not temperature stressed rates of ROS formation are significantly higher in M. arenaria $(P<0.05)$ only above $10^{\circ} \mathrm{C}$. Taken 
that animals avoid warming by vertical migrations in the sediment, this might affect them on warm summer days, when temperatures of up to $20{ }^{\circ} \mathrm{C}$ are recorded at the depth where the animals live. Mitochondrial respiration falls in one line between 1 and $10{ }^{\circ} \mathrm{C}$ (Fig. 6a) in both animals. As state 3 ROS formation rates between 5 and $12{ }^{\circ} \mathrm{C}$ are somewhat lower in $M$. arenaria, and, moreover, less temperature dependent in state 3 ( $\mathrm{Ea} M$. arenaria: $38.8 \mathrm{~kJ} \mathrm{~mol}^{-1}$, Ea L. elliptica: 59.7 $\mathrm{kJ} \mathrm{mol}^{-1}$ ) (Fig. 6c), the percentage conversion of oxygen to ROS results significantly higher $(P<$ $0.05)$ in $L$. elliptica compared to $M$. arenaria mitochondria during heat stress. It might be adaptive in the eurythermal species to minimize respiratory ROS formation over a wide temperature range, in order to prevent oxidative stress at higher sediment temperatures.

SOD activity did not differ between gill tissues of both animals (M. arenaria: $0.79 \pm 0.04$ $\mathrm{U} \mathrm{mg}^{-1}$ fwt, L. elliptica: $0.64 \pm 0.07 \mathrm{U} \mathrm{mg}^{-1} \mathrm{fwt}$ ). However, catalase activity in L. elliptica gills was fourfold higher, compared to $M$. arenaria gills $\left(0.43 \pm 0.2 \mathrm{U} \mathrm{mg}^{-1} \mathrm{fwt}\right)$. Catalase activity was independent of temperature in both animals and much of the activity will be preserved down to 0 ${ }^{\circ} \mathrm{C}$. This reflects cold compensation and may indicate elevated oxidative stress in the cold adapted species. Fourfold higher tocopherol levels in $L$. elliptica midgut gland support the idea that the levels of oxidative stress might be high in the polar bivalve (Estevez et al., 2002). The fact that mitochondrial ROS release in L. elliptica is only insignificantly higher when compared to the cold extrapolated data of $M$. arenaria does not exclude elevated susceptibility to radical induced injury in the polar clam. Such enhanced sensitivity may result from higher mitochondrial numbers or from homeoviscous adaptation and, accordingly, elevated levels of lipid unsaturation in the cold.

\subsection{Temperature compensation of whole animal metabolic rate in L. elliptica?}

Mitochondrial capacities of respiration and phosphorylation did not differ between the polar and the temperate clam if compared at a common experimental temperature or when the data found in $M$. arenaria are extrapolated to cold temperatures. Thus, mitochondrial performance is apparently not cold compensated in L. elliptica when compared to the temperate soft shell clam. This is in line with previous literature on cold compensation of respiration in ectothermal polar animals and their mitochondria (Houlihan and Allan, 1982; Guderley, 1998; Pörtner et al., 1999, 2000).

An admittedly rough comparison of whole animal respiration was based on literature data for $L$. elliptica (Ahn and Shim, 1998 Peck and Conway, 2002; Brockington, 2001; Peck et al., 2002) and M. arenaria (Anderson, 1978; Pedersen, 1992). Data for L. elliptica respiration in the Antarctic summer range between 3 and 10.7 $\mu \mathrm{molO}_{2} \mathrm{~g}^{-1} \mathrm{sfdwt}^{-1}$ at $0-1{ }^{\circ} \mathrm{C}$ (sfdwt: shell free dry weight). For $M$. arenaria, Anderson (1978) gives a mean consumption rate of approximately $9 \mu \mathrm{molO}_{2} \mathrm{~g}^{-1} \mathrm{sfdwt} \mathrm{h}^{-1}$ for cold acclimated low intertidal animals at $5{ }^{\circ} \mathrm{C}$. At $15{ }^{\circ} \mathrm{C} M$. arenaria respiration amounted to 14 $\mu \mathrm{molO}_{2} \mathrm{~g}^{-1}$ sfdwt $\mathrm{h}^{-1}$ in Anderson's study, while Pedersen (1992) gave a rate of 23 $\mu \mathrm{molO}_{2} \mathrm{~g}^{-1} \mathrm{sfdwt} \mathrm{h}^{-1}$. This comparison shows that mass specific respiration rates in $M$. arenaria are similar to those of L. elliptica at the same temperature, supporting previous findings that document metabolic rates in Antarctic ectotherms not to be cold compensated if compared to temperate species at the respective habitat temperatures (Clarke, 1991; Pörtner et al., 1999; Peck and Conway, 2002). Indeed, reduction of whole animal ATP demand, which controls oxygen uptake rates to a major extent in active animals, is a basal strategy employed in adaptation to permanent cold (Clarke, 1991). However, with respect to the possibility of ROS formation at low temperatures, the question also is whether animals make much use of their aerobic scope at $0{ }^{\circ} \mathrm{C}$ and increase respiration under high activity conditions (burrowing, flight reactions, active filtration) in situ with elevated oxygen turnover over relevant time spans.

\subsection{Relationships between proton leak and ROS formation}

Table 1 gives the net-fraction of oxygen consumption invested to non-phosphorylating state 4 respiration, corrected for the amount of oxygen converted to ROS in the polar and the temperate bivalve species, and relates this to the ROSformation rate at each experimental temperature. Distinguishing both processes is useful, as state 4 respiration comprises all oxygen consuming processes after phosphorylation has seized, and ROS production may account for up to $7 \%$ of the overall 
Table 1

Net-percentage of oxygen consumption fueling the proton leak (state $4+$ respiration minus ROS), and production of ROS in (a) $L$. elliptica and (b) M. arenaria isolated mitochondria vs. experimental temperature

\begin{tabular}{|c|c|c|c|c|c|c|}
\hline Temperature $\left({ }^{\circ} \mathrm{C}\right)$ & 1 & 3 & 5 & 7 & 9 & 12 \\
\hline $\begin{array}{l}\% \text { net state } 4+\text { of state } 3 \\
\text { nmolROS } \mathrm{mg}^{-1} \mathrm{~min}^{-1}\end{array}$ & $\begin{array}{l}28.1 \\
0.13\end{array}$ & $\begin{array}{l}33.8 \\
0.19\end{array}$ & $\begin{array}{l}41.8 \\
0.22\end{array}$ & $\begin{array}{l}52.2 \\
0.23\end{array}$ & $\begin{array}{l}45.0 \\
0.27\end{array}$ & $\begin{array}{l}43.3 \\
0.33\end{array}$ \\
\hline Temperature $\left({ }^{\circ} \mathrm{C}\right)$ & 5 & 10 & 15 & 20 & 25 & \\
\hline $\begin{array}{l}\% \text { net state } 4+\text { of state } 3 \\
\text { nmolROS mg } \\
\text { min }^{-1}\end{array}$ & $\begin{array}{l}35.7 \\
0.16\end{array}$ & $\begin{array}{l}35.6 \\
0.19\end{array}$ & $\begin{array}{l}37.9 \\
0.297\end{array}$ & $\begin{array}{l}40.0 \\
0.42\end{array}$ & $\begin{array}{l}44.1 \\
0.77\end{array}$ & \\
\hline
\end{tabular}

Respective habitat temperatures are italicized.

respiration (in state 3). After subtraction of ROS formation, residual state 4 respiration should reflect the net investment into the proton leak, an unspecific flow of protons through the mitochondrial inner membrane. This futile cycling of protons is ascribed a certain antioxidant function, as it reduces the built-up of the proton potential $\left(\Delta \mu \mathrm{H}^{+}\right)$ and therewith minimizes mitochondrial ROS formation (for extensive theoretical background see Skulachev, 1996, 1998).

The net-fraction of mitochondrial oxygen uptake which is driven by the proton leak in L. elliptica at habitat temperature $\left(1{ }^{\circ} \mathrm{C}\right)$ was $28 \%$ of state 3 respiration and thus in line, while at the lower end of the scale for other endo- and ecto-thermal animals (25-50\% of SMR, Brookes et al., 1998). According to Pörtner et al. (1999, 2000), a low rate of futile proton cycling is inherent and obviously advantageous to mitochondrial performance of polar species, as it helps to stabilize the intramitochondrial acid-base status and, therewith, economizes the use of energy reserves under permanent cold conditions. Apparently, however, transition beyond the habitat temperature range is accompanied by a concerted increase of the proton leak and ROS formation rates in both bivalve species, showing on-set of excessive energy and oxygen demand and presumably also oxidative stress.

It is difficult to clarify, whether the proton leak might have some controlling effect on mitochondrial ROS production in marine ectotherms under heat stress. We found that lower RCRs $\left(r^{2}=\right.$ $0.2618, P<0.01, n=57)$ and phosphorylation efficiencies (ADP/O) $\left(r^{2}=0.1253, P<0.01, n=59\right)$ under temperature stress correlate with a higher percent fraction of ROS production in L. elliptica. This may reflect an early onset of mitochondrial deterioration, but it also indicates a 'mild uncoup- ling effect' of the mitochondrial inner membrane, which might help to control radical production under heat stress. According to Skulachev (1998), a potential benefit of proton leakage consists in its functioning as a continuous sink for oxygen, also under non-phosphorylating conditions. This becomes important in case of suddenly reduced metabolic activity in an animal, causing ATP/ ADP ratios to rise and oxygen consumption to drop. In this situation, an increased cycling of protons will ensure consumption of cellular oxygen as a mechanism to control intracellular $P_{\mathrm{O}_{2}}$ and, therewith, reduce potential ROS formation. Moreover, it reduces the reduction state of ubisemiquinol and, therewith, possibly ameliorates autoxidation and superoxide formation. Thus, mild uncoupling could thus prove a supportive mechanism to reduce oxidative stress levels in marine ectotherms at stressfully high temperatures.

\section{Conclusion and perspectives}

The cold stenothermal L. elliptica has minimized mitochondrial respiration to levels, that not only match the low energy demand of this stenothermal animal, but moreover guarantee low mitochondrial ROS output at habitat temperatures. So the absolute rate of ROS release per mitochondrion is low, that may compensate for possibly enhanced mitochondrial densities. Nonetheless, antioxidant activities in L. elliptica tissue were comparable or even higher than in the eurythermal clam species hinting at a need to prevent ROS stress under habitat conditions. Thus, either cold adaptation, that among other features includes higher unsaturation and fluidity of membrane lipids, renders the animals more susceptible to oxidative stress, or the Potter Cove L. elliptica stock has to deal with other factors eliciting ROS production like elevat- 
ed concentrations of heavy metals or xenobiotica in its environment. In future investigations it seems recommendable to take such factors into account and also, to compare ROS formation and oxidative stress levels on a whole cell or even tissue basis, which will then account for any possible effect of metabolic cold compensation in this species.

\section{Acknowledgments}

We thank the Argentinean divers Claudio Mendez, Arnaldo Gay and Carlos Pili for their uncomplaining support with the permanent and demanding collection of animals for this study. Timo Hirse provided invaluable help in planning the expedition. The project forms part of a bilateral scientific program and was supported by travel grants of the Argentinean SETCIP (AL/A99-UI/ 15) and the German BMBF (DLR-ARG 99/010) to S.P. and D.A.

\section{References}

Abele, D., Heise, K., Pörtner, H.O., Puntarulo, S., 2002. Temperature dependence of mitochondrial function and production of reactive oxygen species in the intertidal mud clam Mya arenaria. J. Exp. Biol. 205, 1831-1841.

Ahn, I.-Y., Shim, J.H., 1998. Summer metabolism of the Antarctic Clam, Laternula elliptica (King and Broderip) in Maxwell Bay, King George Island and its implications. J. Exp. Mar. Biol. Eco. 224, 253-264.

Ansaldo, M., Luquet, C.M., Evelson, P.A., Polo, J.M., Llesuy, S., 2000. Antioxidant levels from different Antarctic fish caught around South Georgia and Shag Rocks. Polar Biol. $23,160-165$.

Aebi, H.E., 1985. Catalase. In: Bergmeyer, H.U. (Ed.), Methods of Enzymatic Analysis, vol. VIII. Verlag Chemie, Weinheim, pp. 273-286.

Anderson, G., 1978. Metabolic rate, temperature acclimation and resistance to high temperature of soft-shell clams, Mya arenaria, as affected by shore level. Comp. Biochem. Physiol. 61A, 433-438.

Boveris, A., Chance, B., 1973. The mitochondrial generation of hydrogen peroxide. Biochem. J. 134, 707-716.

Brockington, S., 2001. The seasonal energetics of the Antarctic bivalve Laternula elliptica (King and Broderip) at Rothera Point, Adelaide Island. Polar Biol. 24, 523-530.

Brookes, P.S., Buckingham, J.A., Tenreiro, A.M., Hulbert, A.J., Brand, M.D., 1998. The proton permeability of the inner membrane of liver mitochondria from ectothermic and endothermic vertebrates and from obese rats: correlations with standard metabolic rate and phospholipid fatty acid composition. Comp. Biochem. Physiol. 119B, 325-334.

Buchner, T., Abele-Oeschger, D., Theede, H., 1996. Aspects of antioxidant status in the polychaete Arenicola marina: tissue and subcellular distribution, and reaction to environmental hydrogen peroxide and elevated temperatures. Mar. Ecol. Prog. Ser. 143, 141-150.
Cassini, A., Favero, M., Albergoni, V., 1993. Comparative studies of antioxidant enzymes in red-blooded and whiteblooded Antarctic teleost fish, Pagothenia bernacchii and Chionodraco hamatus. Comp. Biochem. Physiol. 106C, 333-336.

Chance, B., Williams, G.R., 1955. Respiratory enzymes in oxidative phosphorylation I. Kinetics of oxygen utilization. J. Biol. Chem. 217, 383-393.

Clarke, A., 1991. What is cold adaptation and how should we measure it? Am. Zool. 31, 81-92.

Estabrook, R.W., 1967. Mitochondrial respiratory control and the polarographic measurements in mitochondria. Methods Enzymol. 10, 41-47.

Estevez, M.S., Abele, D., Puntarulo, S., 2002. Lipid radical generation in polar (Laternula elliptica) and temperate (Mya arenaria) bivalves. Comp. Biochem. Physiol. 143B, 729-737.

Gieseg, S.P., Cuddihy, S., Jonathan, V.H., Davison, W., 2000. A comparison of plasma vitamin $\mathrm{C}$ and $\mathrm{E}$ levels in two Antarctic and two temperate water fish species. Comp. Biochem. Physiol. 125B, 371-378.

Guderley, H., 1998. Temperature and growth rates as modulators of the metabolic capacities of fish muscle. In: Pörtner, H.O., Playle, R. (Eds.), Cold Ocean Physiology. Cambridge University Press, Cambridge, pp. 58-87.

Houlihan, D.F., Allan, D., 1982. Oxygen consumption of some Antarctic and British gastropods: an evaluation of cold adaptation. Comp. Biochem. Physiol. 73A, 383-387.

Johnston, I.A., Guderley, H., Franklin, C.E., Crockford, T., Kamunde, C., 1994. Are mitochondria subject to evolutionary temperature adaptations. J. Exp. Biol. 195, 293-306.

Lemaire, P., Viarengo, A., Canesi, L., Livingstone, D.R., 1993. Pro-oxidant and antioxidant processes in gas gland and other tissues of cod (Gadus morhua). J. Comp. Physiol. 163B, 477-486.

Livingstone, D.R., Lips, F., Garcia Martinez, P., Pipe, R.K., 1992. Antioxidant enzymes in the digestive gland of the common mussel Mytilus edulis. Mar. Biol. 112, 265-276.

Mercuri, G., Iken, K., Ledesma, B., Dubois, R.F., 1998. On the distribution patterns and density of the Antarctic infaunal bivalve Laternula elliptica in Potter Cove (King George Island, Antarctica). In: Wiencke, C., Ferreyra, G., Arntz, W. (Eds.), The Ecosystem of Potter Cove, vol. 299. Ber. Polarforsch, King-George Island, Antarctica, pp. 106-112.

Moyes, C.D., Moon, T.W., Ballantyne, J.S., 1985. Glutamate metabolism in mitochondria from Mya arenaria mantle: effects of $\mathrm{pH}$ on the role of glutamate dehydrogenase. J. Exp. Zool. 236, 293-301.

Peck, L.S., Hardewig, I., Pörtner, H.O., 2002. Metabolic demand, oxygen supply and critical temperatures in the Antarctic bivalve, Laternula elliptica. Physiol. Biochem. Zool. 75, 123-133.

Pedersen, T.F., 1992. Temporal variations in heat dissipation and oxygen uptake of the soft shell clam Mya arenaria L. (Bivalvia). Ophelia 36, 203-216.

Pörtner, H.O., Hardewig, I., Lloyd, S.P., 1999. Mitochondrial function and critical temperature in the Antarctic bivalve, Laternula elliptica. Comp. Biochem. Physiol. 124A, 179-189.

Pörtner, H.O., van Dijk, P.L.M., Hardewig, I., Sommer, A., 
2000. Levels of metabolic cold adaptation: tradeoffs in eurythermal and stenothermal ectotherms. In: Davison, W., Williams, C.H. (Eds.), Antarctic Ecosystems: Models for Wider Ecological Understanding. Caxton Press, Christchurch, New Zealand, pp. 109-122.

Pörtner, H.O., 2001. Climate change and temperature-dependent biogeography: oxygen limitation of thermal tolerance in animals. Naturwissensch 88, 137-146.

Ralph, R., Maxwell, J.G.H., 1977. Growth of two Antarctic lamellibranches: Adamussium colbecki and Laternula elliptica. Mar. Biol. 42, 171-175.

Regoli, F., 1992. Lysosomal responses as a sensitive stress index in biomonitoring heavy metal pollution. Mar. Ecol. Prog. Ser. 84, 63-69.

Sastre, J., Pallardo, F.V., Vina, J., 2000. Mitochondrial oxidative stress plays a key role in aging and apoptosis. Life 49, 427-435.

Schloss, I., Ferreyra, G.A., Klöser, H., 1998. Seasonal variation of the conditions for phytoplankton growth in Potter Cove.
In: Wiencke, C., Ferreyra, G., Arntz, W., Rinaldi, C. (Eds.), The Potter Cove Coastal Ecosystem, vol. 299. Ber. Polarforsch, Antarctica, pp. 67-73.

Skulachev, V.P., 1996. Role of uncoupled and non-coupled oxidation in maintenance of safely low levels of oxygen and its one-electron reductants. Q. Rev. Biophys. 29, 169-202.

Skulachev, V.P., 1998. Uncoupling: new approaches to an old problem of bioenergetics. Biochim. Biophys. Acta 1363, $100-124$.

Sohal, R.S., Weindruch, R., 1996. Oxidative stress, caloric restriction, and aging. Science 273, 59-63.

Urban, H.J., 1998. Upper Temperature Tolerance of Two Antarctic Molluscs (Laternula elliptica and Nacella concinna) from Potter Cove, vol. 299. Ber. Polarforsch, KingGeorge Island, Antarctic, Peninsula, pp. 230-236.

Zielinski, S., Pörtner, H.O., 2000. Oxidative stress and antioxidative defence in cephalopods: a function of metabolic rate or age? Comp. Biochem. Physiol. 125B, 147-160. 